Supplement of SOIL, 3, 191-210, 2017

https://doi.org/10.5194/soil-3-191-2017-supplement

(C) Author(s) 2017. This work is distributed under

the Creative Commons Attribution 3.0 License.

(c) (1)

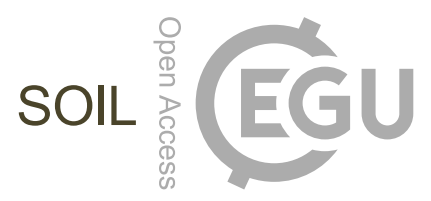

Supplement of

\title{
Mapping of soil properties at high resolution in Switzerland using boosted geoadditive models
}

Madlene Nussbaum et al.

Correspondence to: Madlene Nussbaum (madlene.nussbaum@env.ethz.ch)

The copyright of individual parts of the supplement might differ from the CC BY 3.0 License. 


\section{Supplementary Material}

\section{List of Tables}

S1 Descriptive statistics of topsoil effective cation exchange capacity (ECEC), ZH forest . . . . . . . . . . . . . . . 2

S2 Frequency of presence of waterlogged soil horizons, Greifensee . . . . 2

S3 Frequency of drainage classes, Greifensee . . . . . . . . . . . . . 2

\section{List of Figures}

S1 Partial residual plots for ECEC . . . . . . . . . . . . . . . 3

S2 Sample variograms of the residuals . . . . . . . . . . . . . 4

S3 Prediction intervals for ECEC . . . . . . . . . . . . . . . 5 5

S4 Partial residual plots for presence waterlogged horizons down to $30 \mathrm{~cm} \quad 6$

S5 Partial residual plots for presence waterlogged horizons down to $50 \mathrm{~cm} \quad 6$

S6 Partial residual plots for presence waterlogged horizons down to $100 \mathrm{~cm} \quad 7$

S7 Partial residual plots for drainage classes . . . . . . . . . . . . 8 
Table S1: Descriptive statistics of topsoil effective cation exchange capacity (ECEC) $\left[\mathrm{mmol}_{c} \mathrm{~kg}^{-1}\right]$ of $\mathrm{ZH}$ forest $(0-20 \mathrm{~cm})$ split into calibration and validation sets (N: number of soil samples, Ns: number of unique sites, min: minimum, max: maximum, stdv: standard deviation, CV: coefficient of variation).

\begin{tabular}{lrrrrrrrr}
\hline dataset & $\mathrm{N}$ & $\mathrm{Ns}$ & $\min$ & $\max$ & mean & median & stdv & $\mathrm{CV}$ \\
\hline calibration & 1316 & 1055 & 17.4 & 780.0 & 170.2 & 149.3 & 100.2 & 0.59 \\
validation & 528 & 293 & 17.8 & 492.4 & 150.4 & 121.4 & 94.0 & 0.63 \\
\hline
\end{tabular}

Table S2: Frequency of presence of waterlogged soil horizons (horizon qualifiers "gg" or "r" according to Swiss soil classification, Jäggli et al., 1998) down to a given soil depth split into calibration and validation set (Ns: number of sites, \#: number of present or absent, \% percentage present).

\begin{tabular}{lllrrr}
\hline depth $[\mathrm{cm}]$ & dataset & \multirow{2}{*}{ Ns } & absent & \multicolumn{2}{c}{ present } \\
& & & $\#$ & $\#$ & $\%$ \\
\hline $0-30$ & calibration & 764 & 662 & 102 & 13.4 \\
& validation & 198 & 173 & 25 & 12.6 \\
\hline \multirow{2}{*}{$0-50$} & calibration & 764 & 563 & 201 & 26.3 \\
& validation & 198 & 152 & 46 & 23.2 \\
\hline \multirow{2}{*}{$0-100$} & calibration & 764 & 448 & 316 & 41.4 \\
& validation & 198 & 133 & 65 & 32.8 \\
\hline
\end{tabular}

Table S3: Frequency of drainage classes (aggregated profile qualifiers of Swiss soil classification, Jäggli et al., 1998), split into calibration and validation sets (Ns: number of sites, \#: number of observations and \% percentage of observations per level).

\begin{tabular}{lcrrrrrr}
\hline dataset & Ns & \multicolumn{2}{c}{ well drained } & \multicolumn{2}{c}{ moderately } & poorly drained \\
& & & & \multicolumn{4}{c}{ well drained } \\
& & $\#$ & $\%$ & $\#$ & $\%$ & $\#$ & $\%$ \\
\hline calibration & 732 & 476 & 65.0 & 94 & 12.8 & 162 & 22.1 \\
validation & 198 & 146 & 73.7 & 23 & 11.6 & 29 & 14.6 \\
\hline
\end{tabular}



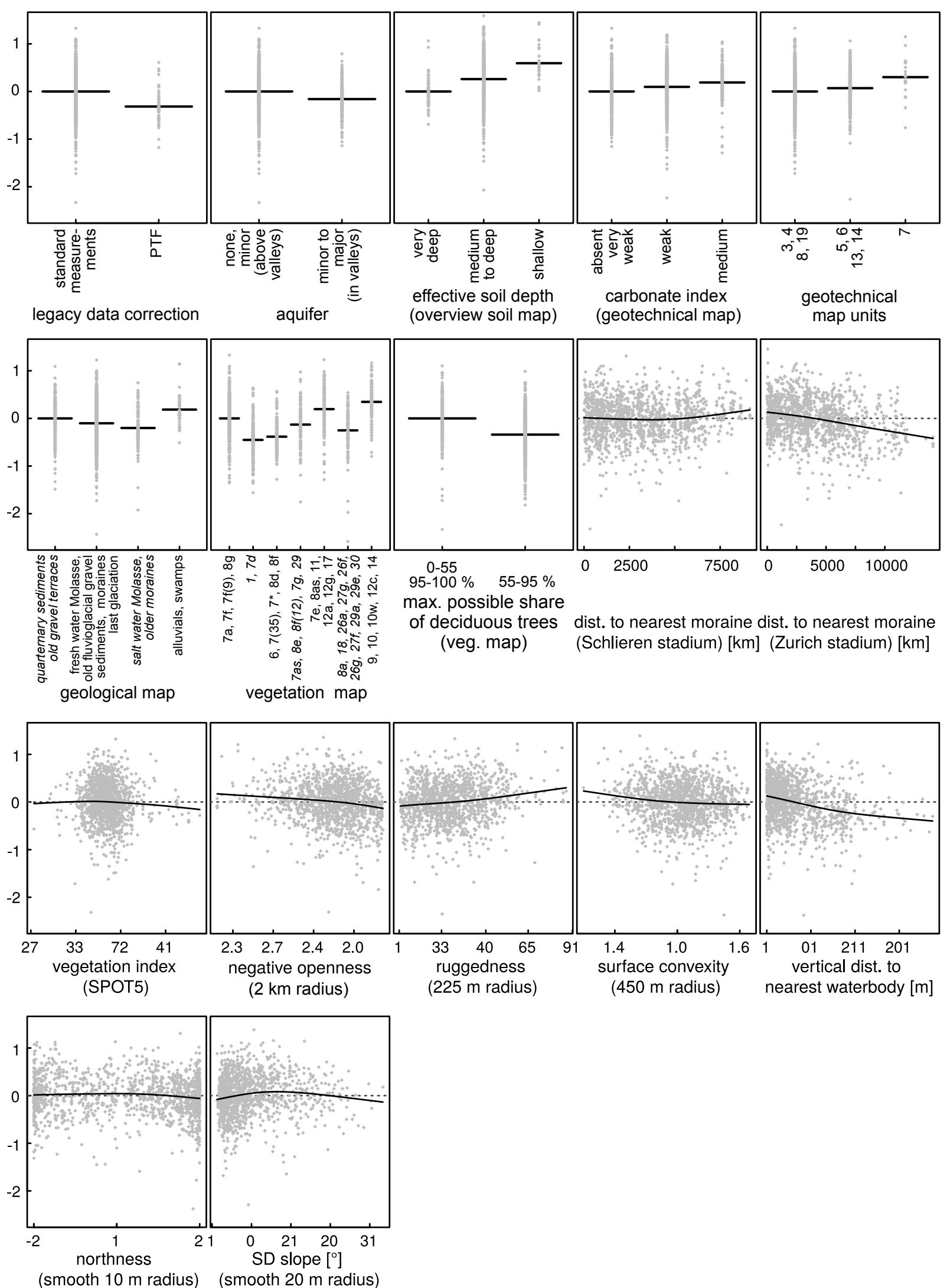

Figure S1: Partial residuals $\left[\log \mathrm{mmol}_{c} \mathrm{~kg}^{-1}\right]$ for factors and smooth effects (continuous covariates) of model for effective cation exchange capacity (ECEC) in 0-20 cm, ZH forests (PTF: pedotransfer function predicting ECEC, SD: standard deviation in focal window). 

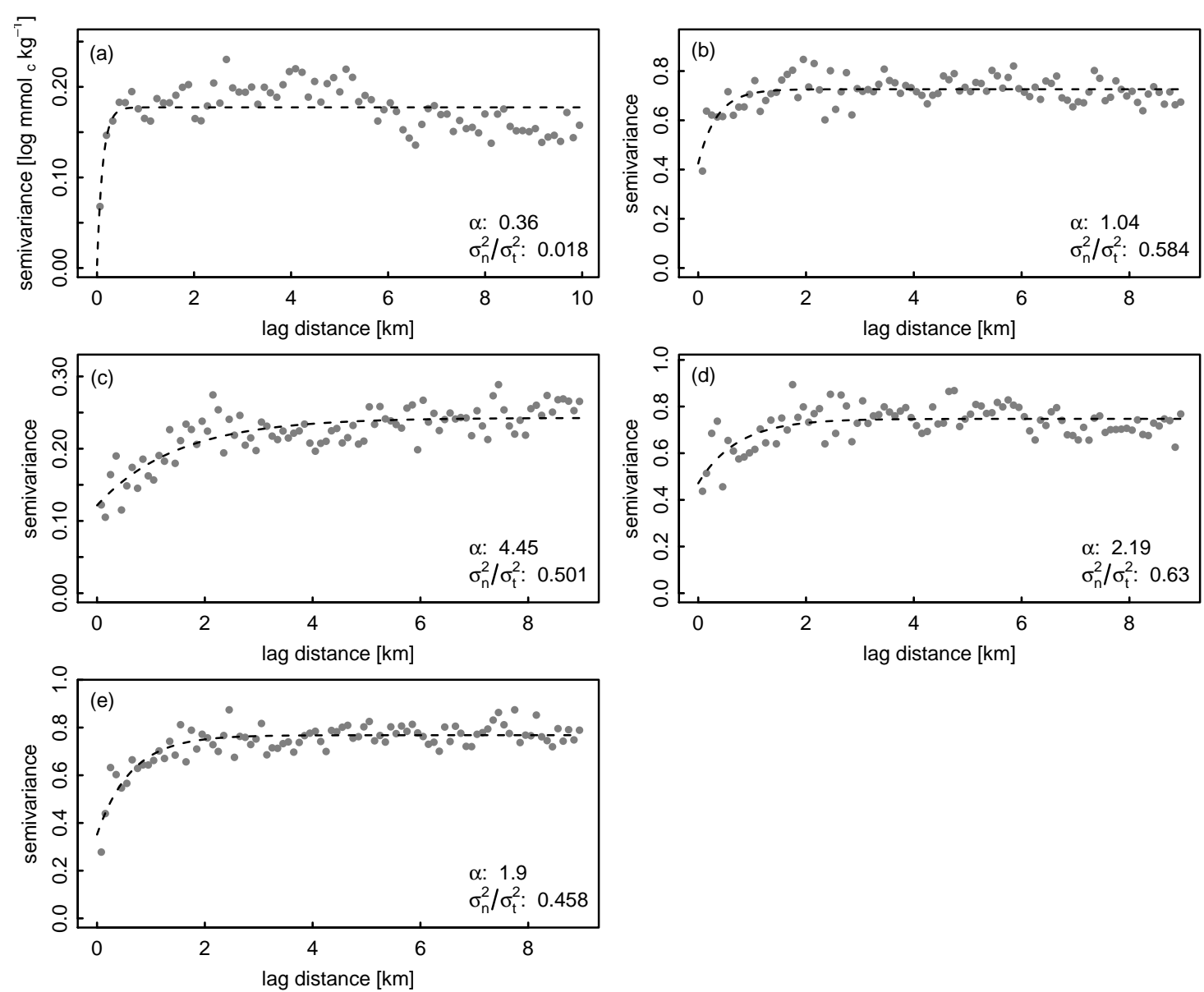

Figure S2: Sample variograms of the residuals at scale of additive predictor (grey dots, robust Qn-estimator) and least squares fit of exponential variogram (dotted line) for (a) ECEC 0-20 cm depth, (b) drainage classes, presence of waterlogged soil horizons in (c) 0-30 cm, (d) 0-50 cm and (e) $0-100 \mathrm{~cm}\left(\alpha\right.$ : effective range $[\mathrm{km}], \sigma_{n}^{2} / \sigma_{t}^{2}$ : ratio of nugget to total sill). 


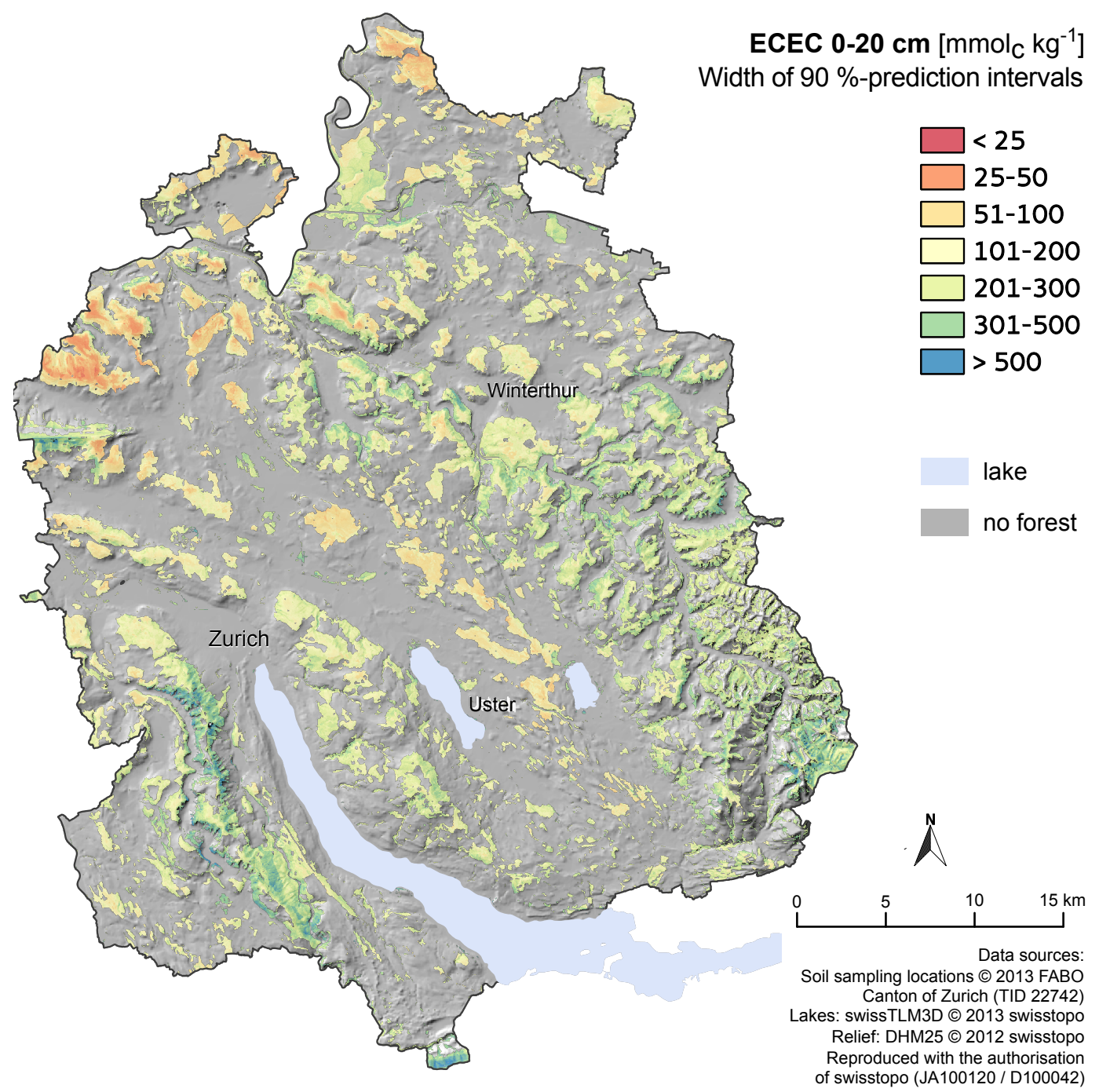

Figure S3: Width of $90 \%$ prediction intervals for effective cation exchange capacity (ECEC) in $0-20 \mathrm{~cm}$ depth of ZH forests computed by model based bootstrapping (ECEC legend classes according to Walthert et al., 2004). 


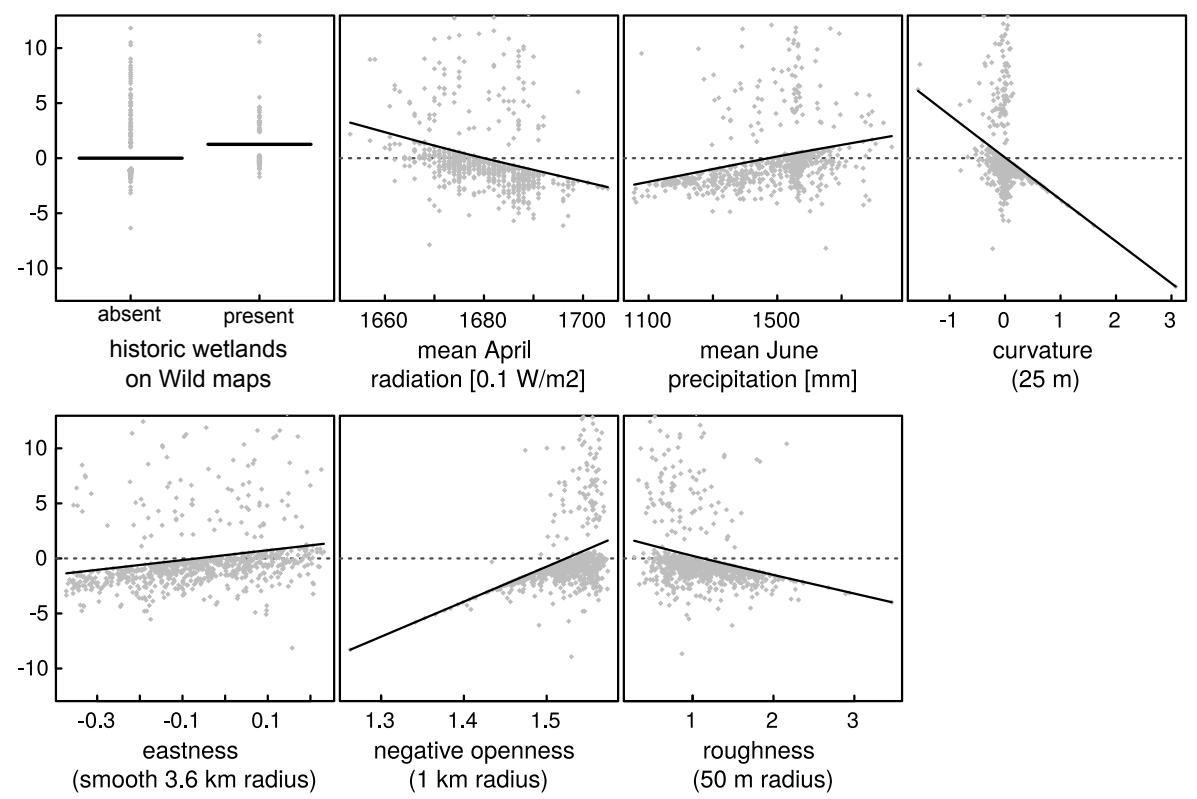

Figure S4: Partial residuals for parametric (binary covariates) and smooth effects (continuous covariates) of model for presence of waterlogged soil horizons down to $30 \mathrm{~cm}$, Greifensee.

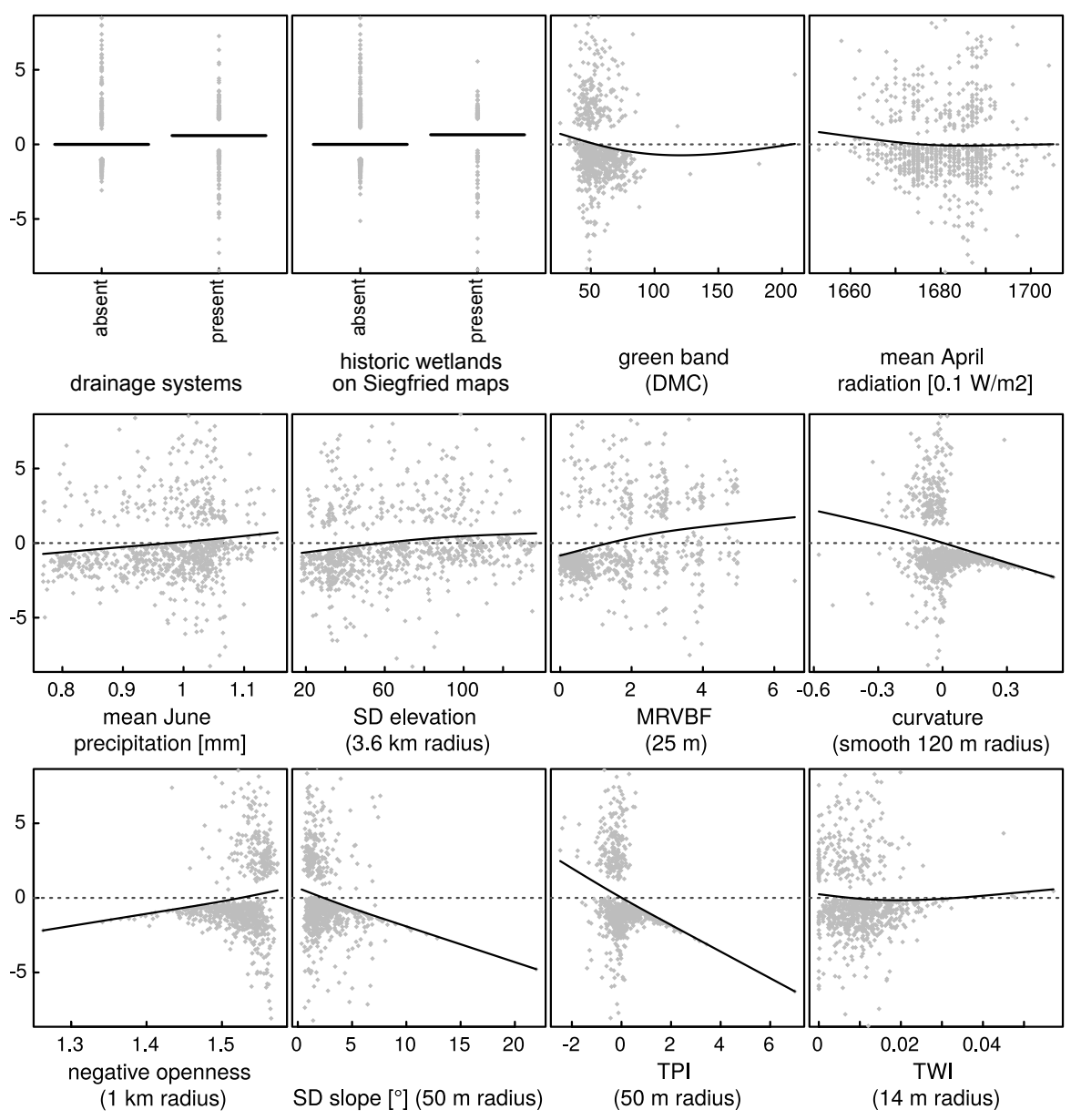

Figure S5: Partial residuals for parametric (binary covariates) and smooth effects (continuous covariates) of model for presence of waterlogged soil horizons down to $50 \mathrm{~cm}$, Greifensee (SD: standard deviation in focal window, MRVBF: multi-resolution valley bottom flatness, TPI: topographic position index, TWI: topographic wetness index). 


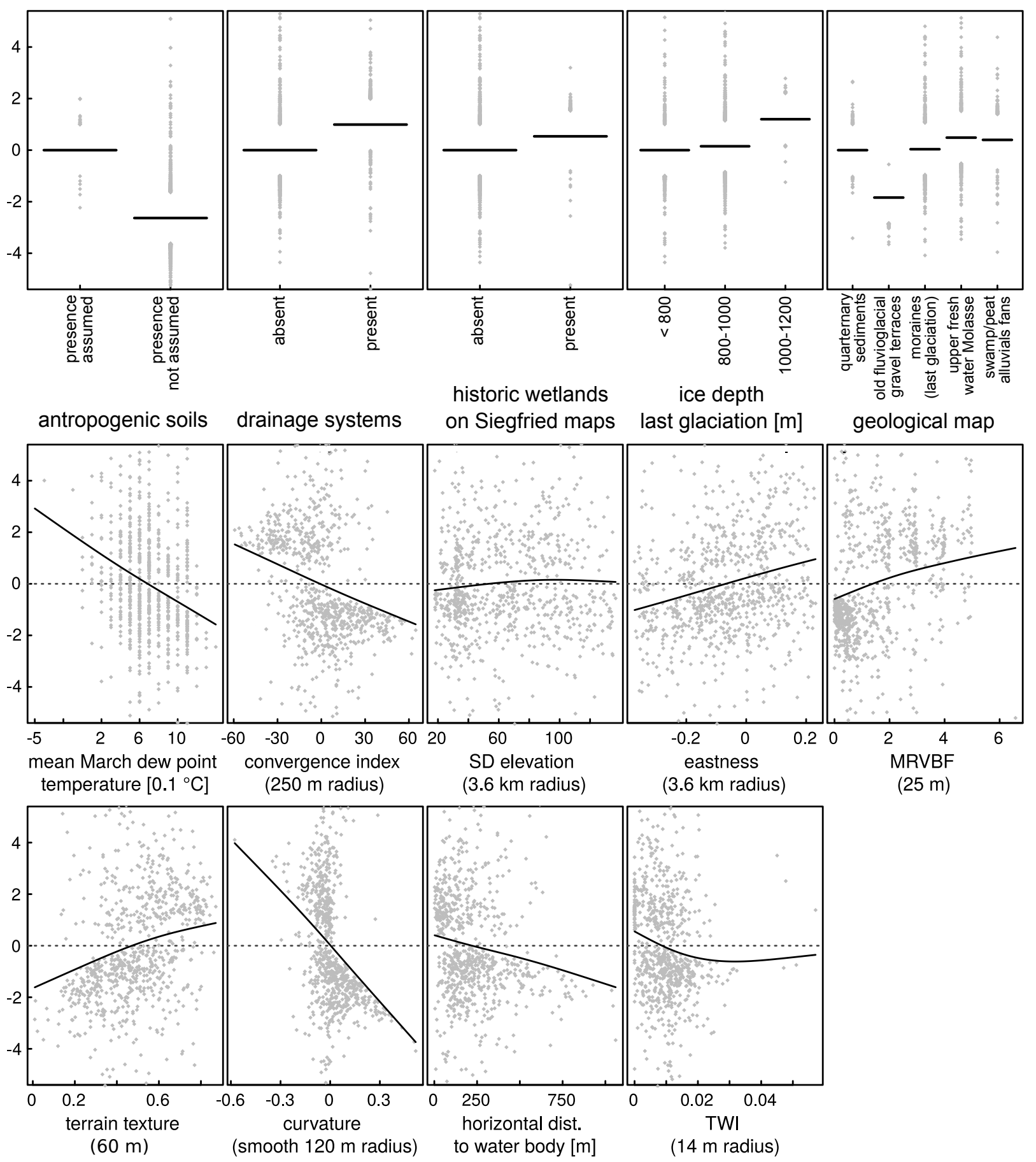

Figure S6: Partial residuals for parametric (binary and nominal covariates) and smooth effects (continuous covariates) of model for presence of waterlogged soil horizons down to $100 \mathrm{~cm}$, Greifensee (SD: standard deviation in focal window, MRVBF: multi-resolution valley bottom flatness, TWI: topographic wetness index). 

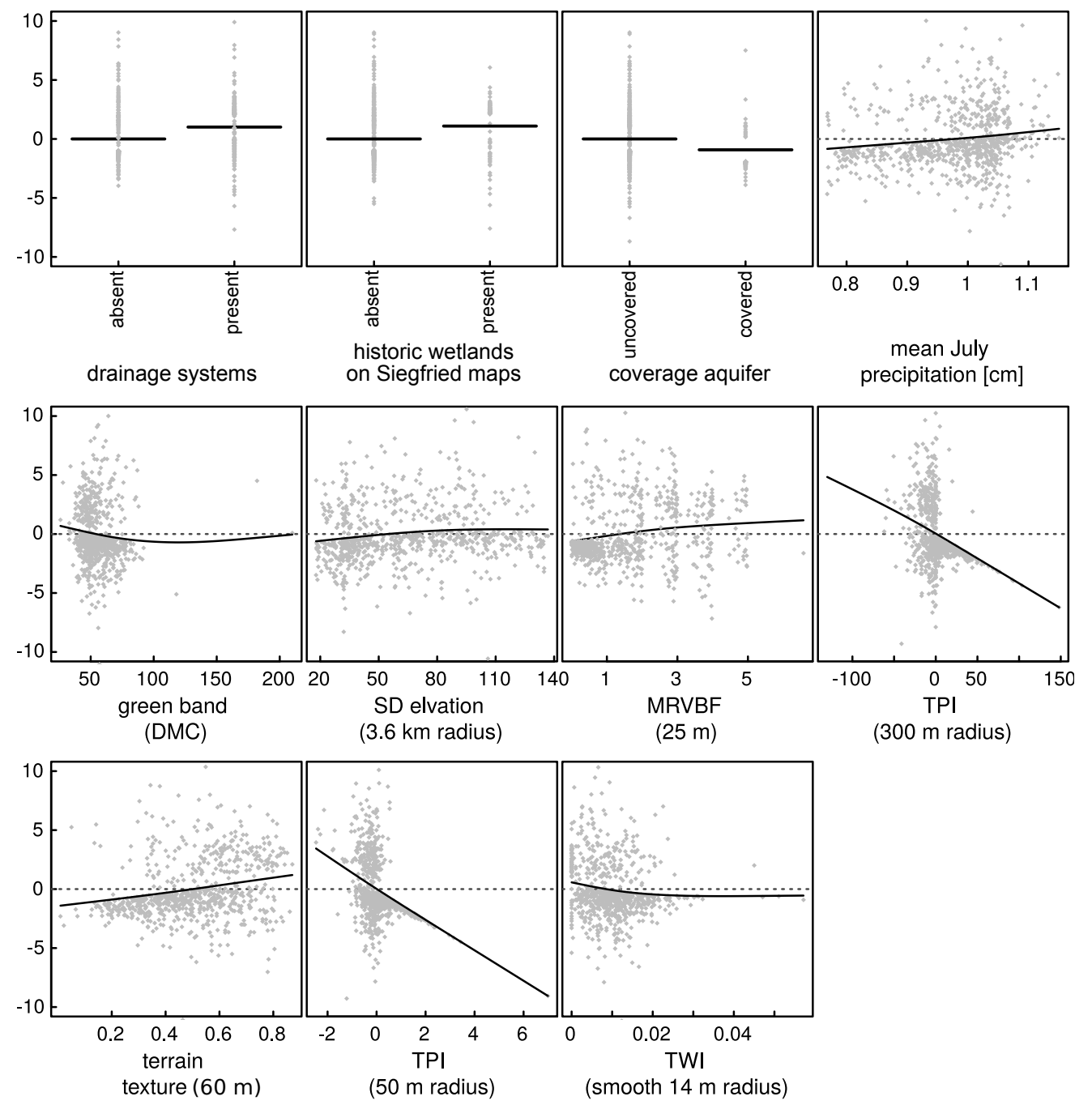

Figure S7: Partial residuals for parametric (binary covariates) and smooth effects (continuous covariates) of model for drainage classes, Greifensee (SD: standard deviation in focal window, MRVBF: multi-resolution valley bottom flatness, TPI: topographic position index, TWI: topographic wetness index).

\section{References}

Jäggli, F., Peyer, K., Pazeller, A., and Schwab, P.: Grundlagenbericht zur Bodenkartierung des Kantons Zürich, Tech. rep., Volkswirtschaftsdirektion des Kantons Zürich und Eidg. Forschungsanstalt für Agrarökologie und Landbau Zürich Reckenholz FAL, 1998.

Walthert, L., Zimmermann, S., Blaser, P., Luster, J., and Lüscher, P.: Waldböden der Schweiz. Band 1. Grundlagen und Region Jura, Eidg. Forschungsanstalt WSL and Hep Verlag, Birmensdorf and Bern, 2004. 